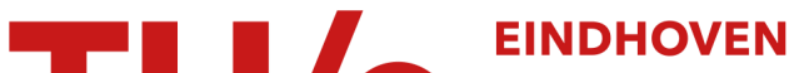 UNIVERSITY OF TECHNOLOGY
}

\section{Optical patterns on drawn polyethylene by direct laser writing}

Citation for published version (APA):

Lafleur, S. S. D., Shen, L., Kamphuis, E. J. T. W., Houben, S. J. A., Balzano, L., Severn, J. R., Schenning, A. P. H. J., \& Bastiaansen, C. W. M. (2019). Optical patterns on drawn polyethylene by direct laser writing. Macromolecular Rapid Communications, 40(9), [1800811]. https://doi.org/10.1002/marc.201800811

\section{Document license:}

TAVERNE

DOI:

10.1002/marc.201800811

Document status and date:

Published: 01/05/2019

\section{Document Version:}

Publisher's PDF, also known as Version of Record (includes final page, issue and volume numbers)

\section{Please check the document version of this publication:}

- A submitted manuscript is the version of the article upon submission and before peer-review. There can be important differences between the submitted version and the official published version of record. People interested in the research are advised to contact the author for the final version of the publication, or visit the $\mathrm{DOI}$ to the publisher's website.

- The final author version and the galley proof are versions of the publication after peer review.

- The final published version features the final layout of the paper including the volume, issue and page numbers.

Link to publication

\section{General rights}

Copyright and moral rights for the publications made accessible in the public portal are retained by the authors and/or other copyright owners and it is a condition of accessing publications that users recognise and abide by the legal requirements associated with these rights.

- Users may download and print one copy of any publication from the public portal for the purpose of private study or research.

- You may not further distribute the material or use it for any profit-making activity or commercial gain

- You may freely distribute the URL identifying the publication in the public portal.

If the publication is distributed under the terms of Article $25 \mathrm{fa}$ of the Dutch Copyright Act, indicated by the "Taverne" license above, please follow below link for the End User Agreement:

www.tue.nl/taverne

\section{Take down policy}

If you believe that this document breaches copyright please contact us at:

openaccess@tue.nl

providing details and we will investigate your claim. 


\title{
Optical Patterns on Drawn Polyethylene by Direct Laser Writing
}

\author{
Sarah S. D. Lafleur, Lihua Shen,* Ebeltien J. T. W. Kamphuis, Simon J. A. Houben, \\ Luigi Balzano, John R. Severn, Albertus P. H. J. Schenning, and Cees W. M. Bastiaansen*
}

Optical patterns are produced on the surface of drawn linear polyethylene containing 2-(2H-benzotriazol-2-yl)-4,6-ditertpentylphenol (BZT), a photothermal dye, by direct laser writing. The photothermal dye absorbs the UV light and dissipates heat in the polyethylene film. This heat locally results in the melting, shrinking, and recrystallization of PE and the loss of the fibrillar crystalline morphology which is typical for these materials. By using this writing method, an optical image can be obtained by controlling the local UV irradiation dose with a pulsed UV laser. The optical image is visible with the naked eye but also between crossed polarizers giving an overt and covert authentication verification that might be interesting for anti-counterfeit applications.

mostly involving a multitude of elaborate and laborious processing steps, from high energy irradiation to chemical treatment, including plasma treatment, ${ }^{[14-18]}$ gamma irradiation, ${ }^{[19]}$ electron beam irradiation, ${ }^{[20-22]}$ ion irradiation, ${ }^{[23,24]}$ and chemical treatment ${ }^{[25,26]}$ have been thoroughly investigated. Near infra-red lasers have been used extensively to write and mark on PE blended with additives, fillers, pigments, or dyes which enhance the absorption of the laser energy. Three main surface reactions are employed to mark the surface. ${ }^{[27]}$ The first one consists of increasing the local temperature high enough to cause thermal degra-

Polyethylene (PE) is the largest volume thermoplastic owing to its broad range of applications it finds, from packaging, membranes to biomedical, and personal protections. ${ }^{[1-5]}$ The properties of PE highly depend on the molecular weight, molecular weight distribution, and the processing conditions. For example, by drawing PE in the solid state, the original lamellar structure is transformed into an oriented and chainextended fibrillar structure which possesses high mechanical properties in the drawing direction. ${ }^{[6-13]}$ Many applications of solid state have drawn linear PE require surface modification while conserving its bulk properties, ideally by simple and reliable methods. A wide variety of surface patterning techniques,

Dr. S. S. D. Lafleur, E. J. T. W. Kamphuis, S. J. A. Houben,

Prof. A. P. H. J. Schenning, Prof. C. W. M. Bastiaansen

Eindhoven University of Technology

P.O. Box 513, 5600 MB Eindhoven, The Netherlands

E-mail: c.w.m.bastiaansen@tue.nl

Dr. L. Balzano, Dr. J. R. Severn

DSM Ahead B.V.

NL-6160 MD Geleen, The Netherlands

Prof. C. W. M. Bastiaansen

Queen Mary

University of London

London E1 4NS, UK

Dr. L. Shen

Department of Mechanical Engineering

University of Colorado

Boulder, CO 80309, USA

E-mail: Lihua.Shen-1@Colorado.EDU

The ORCID identification number(s) for the author(s) of this article can be found under https://doi.org/10.1002/marc.201800811.

DOI: 10.1002/marc.201800811 dation of the polymer. The charring of the polymer forms a dark marking contrast. The second surface reaction consists of using foaming agents. During the degradation of this additive, gas is released resulting in the foaming of the polymer. The third writing method is heating and/or degrading one colorant in a colorant mixture blended in the polymer, resulting in the presence of only one colorant in the irradiated regions, thus a change of color. ${ }^{[28]}$

Most of these methods produce black marking/writing, require a tight control of the laser operating parameters, and also depend on mixed colorant systems stability. Other patterning techniques such as inkjet printing are not suitable because of the poor adhesion properties of PE or require preliminary treatment such as Corona treatment. Therefore, it is still challenging to write/mark non-colored patterns on PE using simple and reliable methods. Moreover, the abovedescribed methods are predominantly performed with close to isotropic polyolefines and very little literature exists on the patterning of drawn HDPE. This paper reports a new marking route to produce optical patterns on drawn HDPE by direct laser writing with a pulsed UV laser.

Optical images were written on solid state drawn blends of high density polyethylene (HDPE) with UV absorber 2-(2H-benzotriazol-2-yl)-4,6-ditertpentylphenol (BZT) at 2 and $5 \mathrm{wt} \%$ loading, called respectively PE- $2 \mathrm{wt} \%$ and PE-5 wt\%. The drawn HDPE films are irradiated by direct laser writing with a pulsed UV laser (355 nm, $10 \mathrm{~Hz}, 2 \mathrm{~ns})$ at various laser doses. Lines are written on the drawn HDPE films by the overlapping of the laser pulses when moving the sample at a constant speed during irradiation. In Figure 1, a schematic representation of the writing process, a photograph and polarized optical microscopy (POM) images of line patterns at 


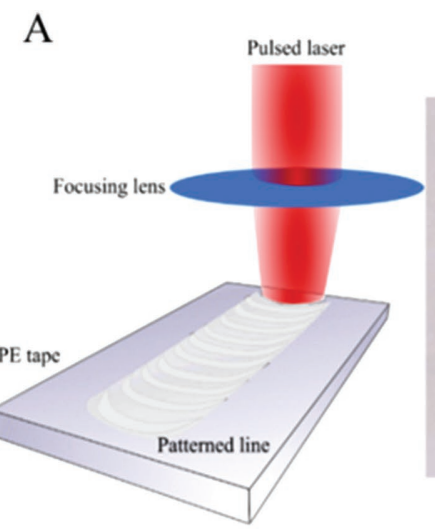

B

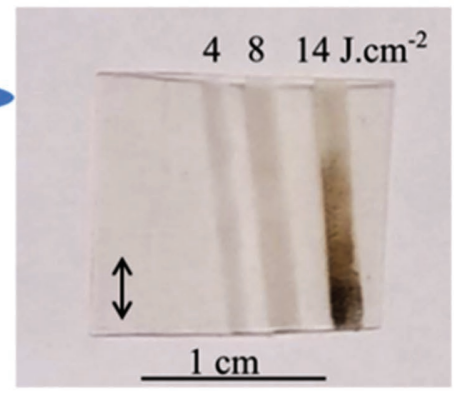

C $4 \mathrm{~J} . \mathrm{cm}^{-2}$

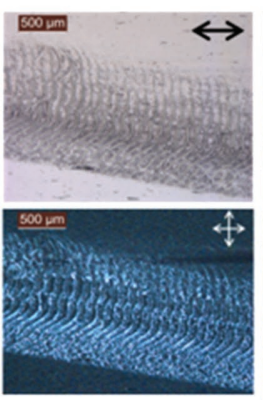

$8{\mathrm{~J} . \mathrm{cm}^{-2}}^{-2}$

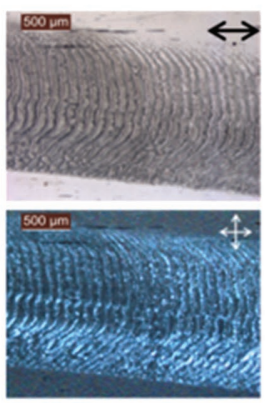

$14 \mathrm{~J} . \mathrm{cm}^{-2}$

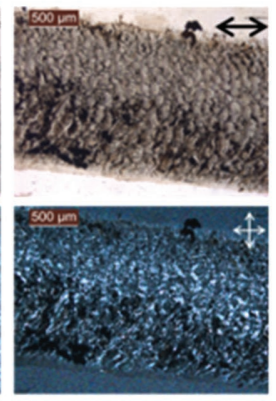

Figure 1. Schematic representation of direct laser writing (left). Photograph of lines (middle) and POM pictures without and with polarizers (right) of $\mathrm{PE}-2 \mathrm{wt} \%$ irradiated with a different laser dose. The white arrows are the polarizer directions and the black arrow is the drawing direction.

various laser doses are presented. Three main regimes can be visually identified. In the case of 2 wt\% BZT with energies below $2 \mathrm{~J} \mathrm{~cm}^{-2}$, no changes appear on the surface of the tape while between roughly 4 and $8 \mathrm{~J} \mathrm{~cm}^{-2}$, lines appear on the tapes. A light intensity above $14 \mathrm{~J} \mathrm{~cm}^{-2}$ results in partial brown/black discoloration. It is likely that a too high irradiation dose degrades the PE. The light intensities of these three regimes in the case of $5 \mathrm{wt} \%$ of BZT appear to be shifted to lower values compared to $2 \mathrm{wt} \%$, indicating that the concentration of dye has a direct impact on the light intensity necessary to pattern the material.

As expected, drawn HDPE tapes with 2 wt\% BZT appear black between crossed polarizers with the drawing direction parallel to one of the polarizers. Samples treated with energies between roughly 4 and $8 \mathrm{~J} \mathrm{~cm}^{-2}$ appear white when viewed at the same conditions. This indicates that the material de-polarizes the light to a certain extent and has lost its chain-extended fibrillar structure. The bright white color between crossed polarizers is usually characteristic for the presence of spherulites. ${ }^{[29]}$ On the other hand, in our case a surface relief structure is also generated (see later) which also can contribute to light scattering, depolarization of light, and a white appearance.

Wide angle $\mathrm{X}$ ray scattering (WAXS) was used to study the change in chain orientation in the PE upon irradiation
(Figure 2). The non-irradiated reference samples (PE-2 wt\% and PE-5 wt\%) show two clear peaks corresponding to the 110 and 200 reflections of the oriented crystalline unit cell. A diffuse halo is visible corresponding to the amorphous phase. Upon irradiation, the full width at half maximum (FWHM) of the 110 peak, often used as a characteristic of the orientation of the crystalline structure, stays approximately the same (Figure S1, Supporting Information). Moreover, the intensity at the equator increases, forming two sharp rings at the same q value as 110 and 200 crystalline peaks, while the area below the peak decreases. These sharp rings reveal the formation of an isotropic crystalline phase. Apparently after UV light irradiation, two populations co-exist in the material, a highly oriented crystalline part and an isotropic part composed of crystalline and amorphous material. These results confirm the hypothesis that on the surface of the bulk anisotropic material, a surface composed of isotropic PE is formed upon UV light irradiation.

The depth of the patterned PE tapes with 2 and 5 wt\% BZT illuminated with different laser intensities was determined by investigating the cross section of the tapes by scanning electron microscopy (SEM) (Figure 2). In the SEM picture, the line pattern appears darker than the rest of the PE tape due to its relief structure. The difference between the thickness of the exposed and non-exposed tape is used to determine the

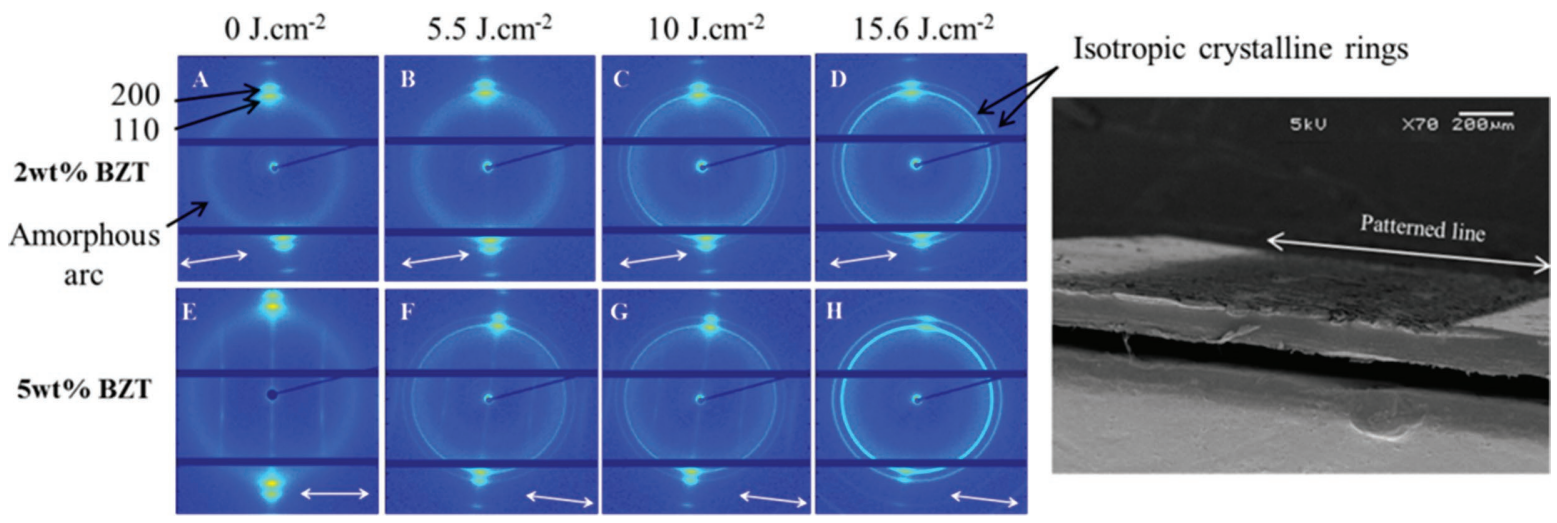

Figure 2. Left: WAXS images of stretched PE with 2 ( $A$ to $D)$ and 5 wt\% BZT (E to $H$ ) irradiated with 0 ( $A$ and $E), 5.5$ (B and F), 10 (C and $G$ ) and 15.6 $\mathrm{J} \mathrm{cm}^{-2}(\mathrm{D}$ and $\mathrm{H})$. Right: SEM picture of the cross section of stretched PE with $2 \mathrm{wt} \%$ BZT. 

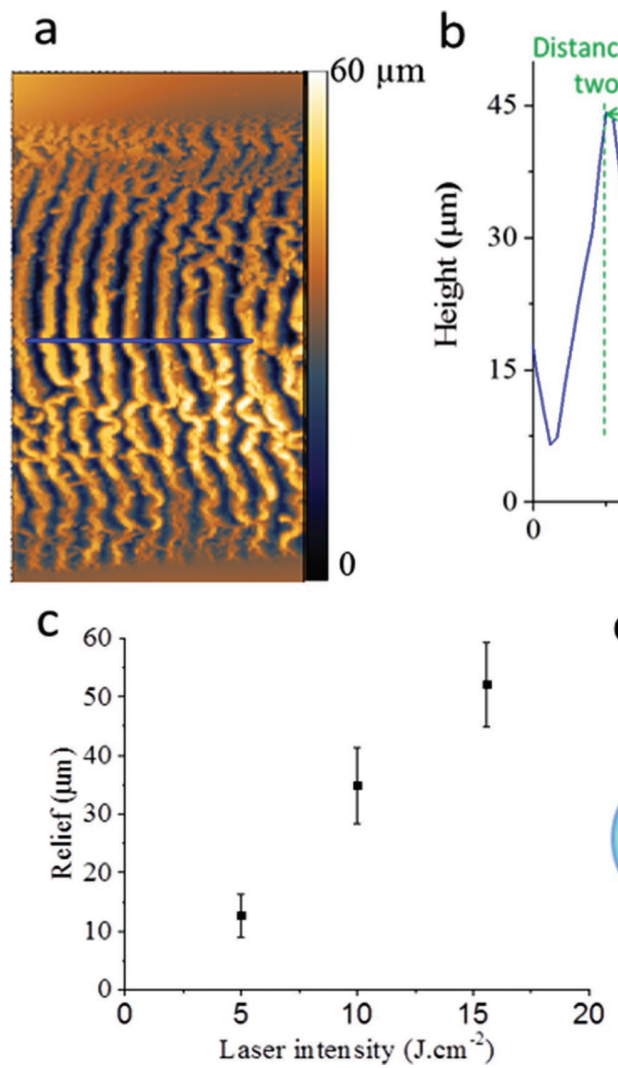

Figure 3. Relief height of the patterned line of a HDPE tape with 2 wt\% BZT irradiated with 10 $\mathrm{cm}^{-2}$ : a) 2D top view image, b) height profile measured at the blue line in the 2D image, c) relief height dependence on laser dose, and d) Illustration of the inhomogeneous intensity in the pulse (orange high intensity, blue low intensity) and the peak formation with the pulses overlapping.
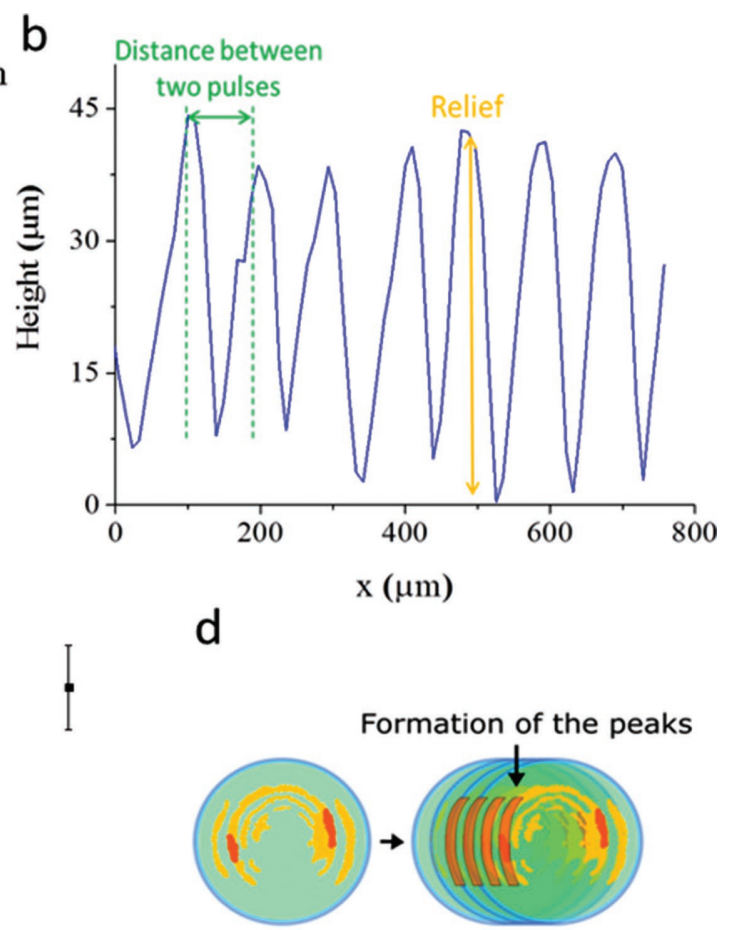

and valleys as shown in Figure 3b. As expected, the relief height increases with a higher laser dose (Figure 3c). The distance between two peaks corresponds to the distance between two pulses which is dependent on the writing speed (sample stage translational speed) and the frequency of the laser (see experimental section). In the case presented here, the distance between two laser pulses is $100 \mu \mathrm{m}$, resulting from a stage translational speed of $1 \mathrm{~mm} \mathrm{~s}^{-1}$ and a pulse frequency of $1 \mathrm{~Hz}$. The laser pulse intensity is not homogenous and high intensity partial rings are observed (Figure 3d). Therefore the peaks are likely produced by the high intensity areas of the pulse corresponding to the left and/or the right partial rings. The pulses are overlapping from left to right, which causes the left partial ring to be the last to irradiate the sample. The peaks formation can most likely be attributed to the irradiation of the material with the high intensity left partial ring of the pulse.

Based on all these data, the formation of the relief structure is most likely the result of the BZT dye absorbing the UV irradiation and producing heat in the PE tape. At temperatures above the melting temperature, the PE melts which causes an entropic contraction resulting in the relief formation. The isotropic PE at high tem-

depth of patterning. The laser intensity has little influence on the depth of the pattern compared to the BZT concentration (Figure S2, Supporting Information). In the case of HDPE with $5 \mathrm{wt} \% \mathrm{BZT}$, the light penetrates the material with a depth of approximately $12 \mu \mathrm{m}$ instead of $32 \mu \mathrm{m}$ for $2 \mathrm{wt} \%$ BZT.

The roughness on the patterned lines was studied in more detail using a DektakXT stylus profilometer. The area irradiated by the laser displays a relief structure consisting of peaks and valleys (Figure 3a). Whether the irradiated area is above, below, or at the same height as the rest of the film is difficult to determine as the PE tapes are not flat enough. Therefore, the relief height is defined as the height difference between the peaks perature exhibits high mobility and upon cooling recrystallizes with a larger volume, creating the peaks. The valleys may well be the result of the gradient of intensity in each laser pulse. The width of the patterned line is mainly controlled by the distance between the sample and the focal point of the lens (Figure S3, Supporting Information). The smallest pulse, so the narrowest line, is obtained when placed at the focal point of the lens.

The irradiation of drawn PE with a UV pulsed laser, combined with a UV absorber can be used for patterning the material with an optical image, such as a spiral, as shown in Figure 4. The spiral is also visible between crossed polarizers because the drawn HDPE is black outside the laser recorded
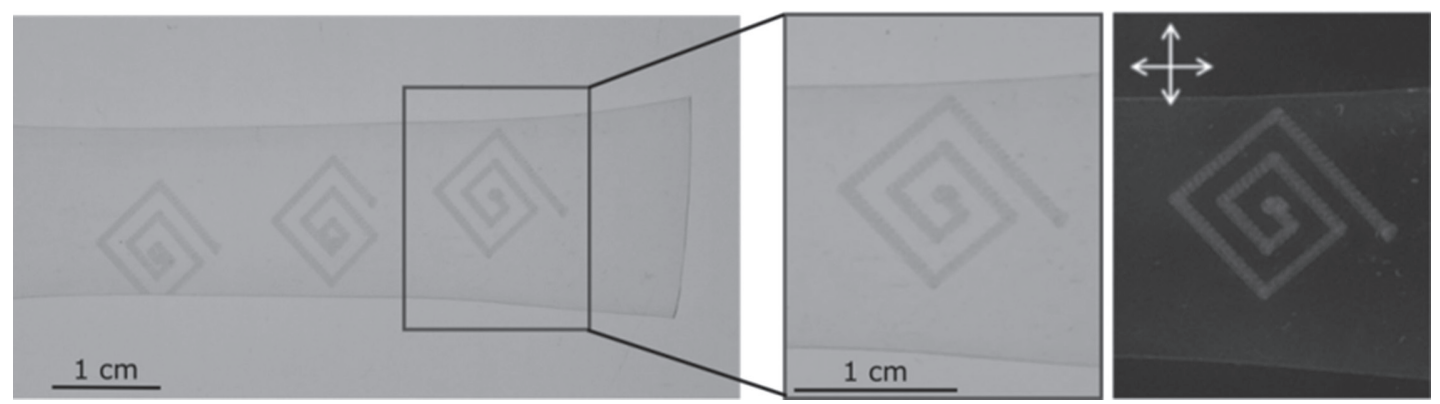

Figure 4. Spiral patterned on PE-5 wt\%. Zoomed-in pictures, left: no polarizers; right: between crossed polarizers and the drawing direction horizontal. 
regions and white in the laser recorded regions. As discussed previously, the white appearance is probably related to light scattering and depolarization of the light originating from spherulites or the relief structure or combinations of these two phenomena.

This photo-patterning method shows possibilities in anticounterfeiting and identification applications. In anti-counterfeiting, different authentication verification methods such as overt (visible to the eye) and covert (using special equipment for visualization) are employed. Here, the spiral is overt as it is directly visible and covert because it appears white on a black background between two crossed polarizers.

We have presented a new method to create optical patterns in solid state drawn PE containing a photothermal dye, with UV light irradiation. Detailed analysis reveals that the bulk morphology of the polymer film is not affected and that the photothermal dye absorbs the UV light and dissipates heat in the PE film leading to a loss of the fibrillar structure and topographical surface changes. The topographical patterns appear white while the rest of the tape is transparent, which corresponds to an overt authentication verification. Between crossed polarizers, the patterns are still white while the rest of the tape is black corresponding to a covert authentication verification making this patterning method interesting for anti-counterfeiting applications. The patterning method can probably also be applied to other drawn polymers making this patterning technique potentially widely applicable.

\section{Experimental Section}

Preparation of Solid State Drawn HDPE: HDPE VS4580 from Borealis with a number and weight average molecular weight of approximately $3.7 \times 10^{4}$ and $1.3 \times 10^{5} \mathrm{~g} \mathrm{~mol}^{-1}$ was compounded with 2 and $5 \mathrm{wt} \%$ of the UV absorber 2-(2H-Benzotriazol-2-yl)-4,6-ditertpentylphenol (BZT, Tinuvin 328 BASF) in a co-rotating twin screw extruder at $190{ }^{\circ} \mathrm{C} .[30]$ Subsequently, the granules were used to form isotropic sheets of approximately $0.5 \mathrm{~mm}$ thickness, produced by compression molding at $190^{\circ} \mathrm{C}$ for $15 \mathrm{~min}$. Dumbbell-like samples were subsequently drawn to a draw ratio of 10 at $80^{\circ} \mathrm{C}$ using a Zwick Z100 tensile tester at a crosshead speed of $80 \mathrm{~mm} \mathrm{~min}^{-1}$.

Direct Laser Writing: The direct laser writing setup consists of a pulsed UV laser, (Quantra-Ray, Spectra-Physis), at $355 \mathrm{~nm}$ with a frequency of $10 \mathrm{~Hz}$ and a pulse duration of 2 ns. The intensity is modulated by the combination of a half wave plate and a polarizing beam splitter placed in front of the laser beam. The light intensities reported in this study are calculated considering the pulses overlap on the same position (see Equation (S1), Supporting Information). The light beam is then reflected by a mirror at $45^{\circ}$ and goes through a plano-convex lens from Melles griot 01 LQP with a focal distance of $50 \mathrm{~mm}$. The position of the sample is $4.6 \mathrm{~cm}$ from the lens, to obtain dots with a diameter of approximately $1.5 \mathrm{~mm}$. The sample stage moves at a constant speed of $1 \mathrm{~mm} \mathrm{~s}{ }^{-1}$ from left to right and the sample is placed horizontally, the angle $\alpha$ between the drawing direction and the polarization direction of the light is $0^{\circ}$. The intensity profile of the laser pulse was measured with a laser beam profiler and a 2D heatmap was generated (Figure 3d). The intensity profile doesn't show a prefect Gaussian shape and is inhomogeneous. Two spots on the right and left of the pulse show a higher intensity.

Characterization of Patterned PE Films: XRD measurements were performed on a Ganesha lab instrument equipped with a Genix- $\mathrm{Cu}$ ultralow divergence source producing $X$-ray photons with a wavelength of $1.54 \AA$ and a flux of $1 \times 10^{8}$ photons per second. Diffraction patterns were collected on a Pilatus $300 \mathrm{~K}$ silicon pixel detector with $487 \times 619$ pixels of $172 \mu \mathrm{m}^{2}$ placed at a distance of $91 \mathrm{~mm}$ (WAXS) from the sample. The detector consists of three plates with a 17 pixels spacing in between, resulting in two dark bands on the image. WAXS is a transmission measurement, giving an average of the top irradiated layer and the bottom non irradiated one. Surface relief structures were investigated by DektakXT profilometer (Brucker) in which a tip with a radius of $2 \mu \mathrm{m}$ moves with a force of $3 \mathrm{mg}$ across the sample. 3D topographical data were processed, resulting in surface profile images, using Gwyddion software. The cross section of the oriented PE tape was made by section with a scalpel in liquid nitrogen. The tapes are then sputtered with gold for $60 \mathrm{~s}$ at $65 \mathrm{~mA}$ and placed in the SEM (Jeol JSM 5600). Optical micrographs were obtained using a Leica DM2700M optical microscope with a polarizer and analyzer (POM) at an angle of $90^{\circ}$. In POM experiments, the drawing direction was aligned with one of the polarizers (white arrows). If no white arrows were present on the POM photographs, no polarizer or analyzer was used.

\section{Supporting Information}

Supporting Information is available from the Wiley Online Library or from the author.

\section{Acknowledgements}

This work was supported by DSM Dyneema B. V., The Netherlands.

\section{Conflict of Interest}

The authors declare no conflict of interest.

\section{Keywords}

drawn polyethylene, laser writing, photo-patterning, UV absorbers

Received: November 5, 2018 Revised: January 4, 2019

Published online: March 6, 2019

[1] J. Peacock, Handbook of Polyethylene, Marcel Derker, Inc., Bayton, Texas 2000.

[2] S. M. Kurtz, UHMWPE Biomaterials Handbook: Ultra-High Molecular Weight Polyethylene in Total Joint Replacement and Medical Devices, 3rd ed., Elsevier Inc., London 2016.

[3] M. P. Vlasblom, J. L. J. Van Dingenen, 13- The Manufacture, Properties And Applications Of High Strength. High Modulus Polyethylene Fibers, Woodhead Publishing Series in Textile, The Netherlands 2009, 437.

[4] H. Van der Werff, U. Heisserer, High-Performance Ballistic Fibers: Ultra-High Molecular Weight Polyethylene (UHMWPE), Woodhead Publishing, The Netherlands 2016.

[5] I. M. Ward, Plast., Rubber Compos. 2004, 33, 189.

[6] G. Capaccio, I. M. Ward, Nature Phys. Sci. 1973, 243, 143.

[7] G. Capaccio, T. Crompton, I. M. Ward, J. Polym. Sci.: Polym. Phys. Ed. 1976, 14, 1641.

[8] W. Wu, W. Black, Polym. Eng. Sci. 1979, 19, 1163.

[9] P. A. Irvine, P. Smith, Macromolecules 1986, 19, 240.

[10] A. Peterlin, Colloid Polym. Sci. 1987, 265, 357. 
[11] P. Smith, P. Lemstra, J. Pijpers, J. Polym. Sci.: Polym. Phys. Ed. 1982, 20, 2229.

[12] D. Sawai, K. Nagai, M. Kubota, T. Ohama, T. Kanamoto, J. Polym. Sci., Part B: Polym. Phys. 2006, 44, 153.

[13] T. Peijs, Comprehensive Composite Materials II, Elsevier, London 2018, 86.

[14] A. Peterlin, Polym. Eng. Sci 1974, 14, 627.

[15] X. Hu, B. Alcock, J. Loos, Polymer 2006, 47, 2156.

[16] M. Lehocký, H. Drnovská, B. Lapčíková, A. M. Barros-Timmons, T. Trindade, M. Zembala, L. Lapčík Jr., Colloids Surf. A 2003, 222, 125.

[17] V. Švorčík, K. Kolářová, P. Slepička, A. Macková, M. Novotná, V. Hnatowicz, Polym. Degrad. Stab. 2006, 916, 1219.

[18] M. Morra, E. Occhiello, F. Garbassi, J. Adhes. Sci. Technol. 1993, 7, 1051.

[19] S. Guruvenket, G. M. Rao, M. Komath, A. Raichur, Appl. Surf. Sci. 2004, 236, 278.

[20] H. Drnovská, L. Lapčík, V. Buršíková, J. Zemek, A. Barros-Timmons, Colloid Polym. Sci. 2003, 281, 1025.

[21] M. F. Zaki, Y. H. Elshaer, D. Taha, Radiat. Phys. Chem. 2017, 139, 90.
[22] P. Klein, D. Woods, I. M. Ward, J. Polym. Sci., Part B: Polym. Phys. $1987,25,1359$.

[23] P. G. Klein, J. A. Gonzalez-Orozco, I. M. Ward, Polymer 1991, 32, 1732.

[24] K. Sakurai, Y. Kondo, K. Miyazaki, T. Okamoto, S. Irie, T. Sasaki, J. Polym. Sci., Part B: Polym. Phys. 2004, 42, 2595.

[25] G. Takaoka, M. Kawashita, H. Shimatani, R. Araki, Surf. Coat. Technol. 2007, 201, 8242

[26] L. Calcagno, G. Compagnini, G. Foti, Nucl. Instruments and Methods in Phys. Res Section B: Beam Interactions with Mater. Atoms 1992, 65, 413.

[27] M. Nardin, I. M. Ward, Mater. Sci. Technol. 1987, 3, 814.

[28] S. Debnath, R. Ranade, S. L. Wunder, G. R. Baran, J. Zhang, E. R. Fisher, J. Appl. Polym. Sci. 2005, 96, 1564.

[29] S. R. Sabreen, www.industrial-lasers.com, Technology report, accessed: August, 2018.

[30] R. M. Harris, K. Feng, A. R. Burgess(M. A. Hanna Color), US patent 6,022,905 1999 . 